\title{
Synthesis of an intriguing steroidal constitutional isomer
}

Article

Accepted Version

Creative Commons: Attribution-Noncommercial-No Derivative Works 4.0

Townsend, D., Shankland, K., Weymouth-Wilson, A., Komsta, Z., Evans, T. and Cobb, A. J. A. (2020) Synthesis of an intriguing steroidal constitutional isomer. Tetrahedron Letters, 61 (23). 151942. ISSN 0040-4039 doi:

https://doi.org/10.1016/j.tetlet.2020.151942 Available at https://centaur.reading.ac.uk/90699/

It is advisable to refer to the publisher's version if you intend to cite from the work. See Guidance on citing.

Published version at: http://dx.doi.org/10.1016/j.tetlet.2020.151942

To link to this article DOI: http://dx.doi.org/10.1016/j.tetlet.2020.151942

Publisher: Elsevier

All outputs in CentAUR are protected by Intellectual Property Rights law, including copyright law. Copyright and IPR is retained by the creators or other copyright holders. Terms and conditions for use of this material are defined in the End User Agreement.

\section{www.reading.ac.uk/centaur}

\section{CentAUR}

Central Archive at the University of Reading 
Reading's research outputs online 


\section{Graphical Abstract}

To create your abstract, type over the instructions in the template box below.

Fonts or abstract dimensions should not be changed or altered.

\section{Synthesis of an intriguing steroidal} constitutional isomer

Daniel Townsend, Kenneth Shankland, Alex Weymouth-Wilson, Zofia Komsta, Tim Evans, Alexander J. A. Cobb

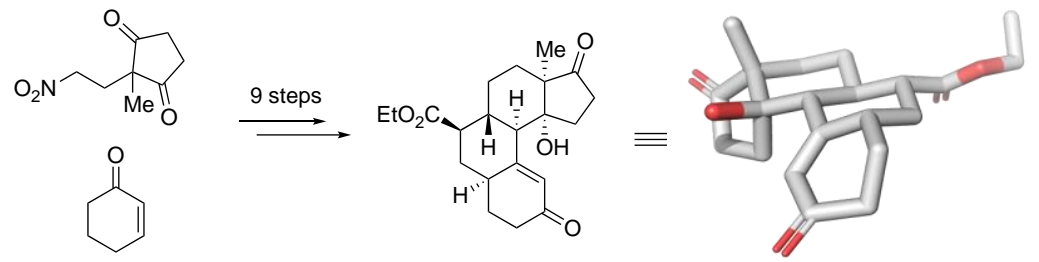




\title{
Synthesis of an intriguing steroidal constitutional isomer
}

\author{
Daniel Townsend ${ }^{\mathrm{a}}$, Kenneth Shankland ${ }^{\mathrm{b}}$, Alex Weymouth-Wilson ${ }^{\mathrm{c}}$, Zofia Komsta ${ }^{\mathrm{c}}$, Tim Evans ${ }^{\mathrm{c}}$, and \\ Alexander J. A. Cobb
}

${ }^{a}$ Department of Chemistry, King 's College London, 7 Trinity Street, London SE1 1DB, UK

${ }^{b}$ School of Chemistry, Food and Pharmacy, University of Reading, Whiteknights, Reading, Berks RG6 6AD, UK

${ }^{c}$ Dextra Laboratories Ltd, Thames Valley Science Park, The Gateway, 1 Collegiate Square, Reading, Berks RG2 9LH, UK

\section{ARTICLE INFO}

\section{ABSTRACT}

\section{Article history:}

\section{Received}

Received in revised form

Accepted

Available online

Keywords:

Steroids

Stereocontrol

Constitutional Isomers

Terpenes

\begin{abstract}
We recently described the synthesis of an unusual tricyclic system, whereby a cis-decalin was fused to a cis-hydrindane. Herein, we wish to describe the elaboration of this system towards steroid-like frameworks. This report describes how, en route to an attempted cardiotonic steroid synthesis, we stereoselectively functionalized the LHF-cyclohexyl ring with an ester ready for steroidal A-ring formation. Ultimately however, the required transposition of the cyclohexylketone did not occur as expected and resulted in the subsequent Robinson annulation forming an unusual steroidal constitutional isomer - the saturated cyclopenta $[c]$ phenanthrene. Remarkably, such unusual tetracyclic connectivity has been reported just once in 70 years.
\end{abstract}

2009 Elsevier Ltd. All rights reserved.

\section{Introduction}

The synthesis of steroidal targets has fascinated synthetic chemists for decades. ${ }^{1}$ This is of course due to the biological profile of these systems, ${ }^{2}$ but much also has to do with the complex stereogenicity and the challenge of how to form these with accuracy and finesse. However, whilst as expected, the literature is rife with syntheses of the typical steroidal framework, examples of the synthesis of constitutional isomers (e.g. Figure 1) are extremely rare and only the saturated cyclopenta $[b]$ phenanthrene system (Figure $1 \mathrm{~b}$ ), prepared by Covey and co-workers as a modulator of the $\mathrm{GABA}_{\mathrm{A}}$ receptor, ${ }^{3}$ has been described. Indeed, the analogous saturated cyclopenta $[c]$ phenanthrene system, and the subject of this report, does appears to have only been reported once in 1950 by Nazarov and co-workers who accessed it via Diels-Alder reaction between 1,3-Dimethyl-1-cyclopentene-4,5-dione and 1-vinyl- $\Delta 1$ octahydronaphthalene. ${ }^{4}$ Although this paucity could be due to the obvious need for the specific framework that steroids are required to have for biological activity, this large absence of any reports of this constitutional isomer within the literature is very curious. (a)

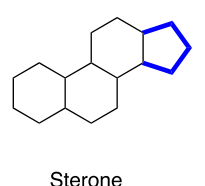

Sterone (b)

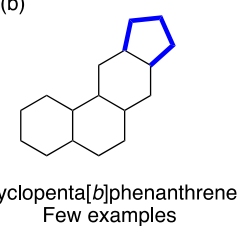

(c) This work:

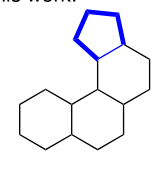

Cyclopenta[c]phenanthren Only one example
Figure 1. Constitutional isomers of the steroidal system are nonexistent. In particular in relation to how the cyclopentyl-D-ring is arranged around the C-ring.
We recently reported the highly enantioselective synthesis of the very unusual tricyclic system $\mathbf{1}$ whereby a $c i s$-decalin was fused to a cis-hydrindane. ${ }^{5} \mathrm{We}$ viewed this system as a potential way into new steroidal frameworks - particularly the cardiotonic steroids, which are characterized by the presence of a cishydrindane with a tertiary alcohol present at the C-14 position. This report details our attempts to access such a framework, which although unsuccessful uncovered a route to this new fascinating tetracyclic steroidal analogue.

In order to utilize our tricyclic system, we were aware that there were several transformations we needed to consider. The first and most obvious was the transposition of the cyclohexyl carbonyl to a position where we could use it to construct the A-ring of a steroidal system. The second was the need for epimerization of the cis-decalin to the corresponding trans-decalin, and finally we would be required to remove the nitro-group if we wanted to access any cardiotonic natural product (Figure 2). Note that in all of our studies we deliberately target the enantiomeric systems to avoid issues of potential toxicity.

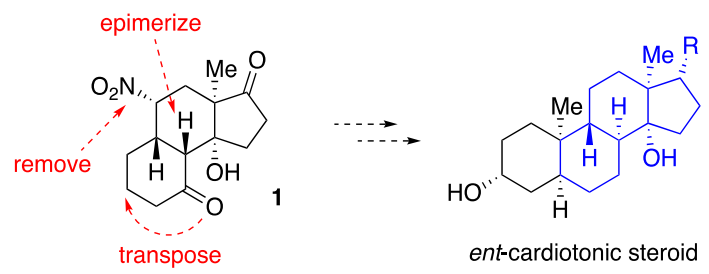

Figure 2. Requirements to use our framework towards a steroidal target. 


\section{Results and Discussion}

We therefore first attempted the epimerization of the enolizable trans-decalin bridgehead proton, and although basic conditions (DBU or DABCO) resulted in very low yields of the C-11 nitro epimer 2, it was found that $\mathrm{HCl}$ gas in dichloromethane gave us entry to the desired trans-decalin 3, whose structure was confirmed by X-ray crystallography (Figure 3 ). With this in hand, we then began to look at removal of the nitro-group under radical conditions. Although we achieved an initial $75 \%$ yield of denitrated product 4 using 5 equivalents of tributyltin hydride in toluene at reflux for $2.5 \mathrm{~h}$, we ultimately opted for Fu's more environmentally compatible conditions using reduced amounts of tributyltin hydride and phenylsilane as a coreductant. Although providing only $65 \%$ yield, this required only stoichiometric amounts of the tin regent - an important consideration for scale up. ${ }^{6}$

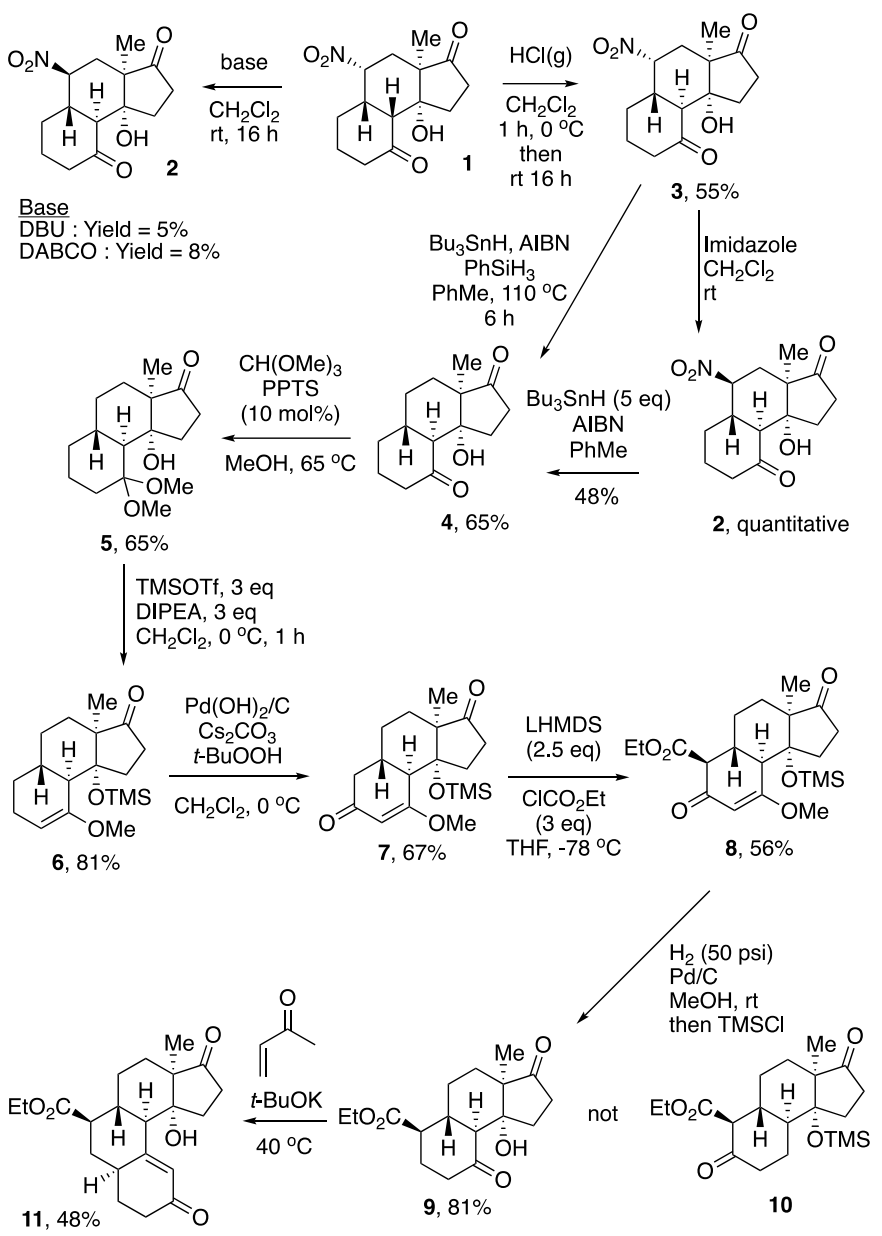

Scheme 1. Stereoselective introduction of an ethyl ester onto the B-ring and the total synthesis of unusual tetracycle $\mathbf{1 1}$.

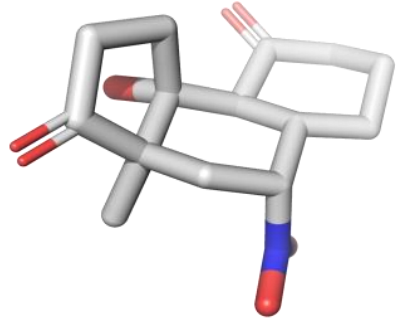

Figure 3. Single crystal X-ray structure of compound $\mathbf{3}$ showing the now trans-decalin unit (CCDC : 1967525).
Interestingly, the radical reduction was much less effective on epimeric compound $\mathbf{2}$, where the nitro group occupied an equatorial position, resulting in just $48 \%$ yield using 5 equivalents of tributyl tin hydride. It was hoped that IBX oxidation of the cyclohexanone ring of compound 4 , which we felt had good precedence from Nicolaou's work, ${ }^{7}$ would allow us to gain a handle to introduce the steroidal A-ring. Unfortunately, this was unsuccessful and an alternative strategy was required. This first involved formation of acetal $\mathbf{5}$ and, as expected, exposure of the tricycle $\mathbf{4}$ to trimethyl orthoformate and pyridinium $p$-toluenesulfonate (PPTS) in methanol formed this selectively at the cyclohexanone ring in $65 \%$ yield. From here the plan was to eliminate the acetal to form the enol ether and then to perform an allylic oxidation, thus introducing the carbonyl to a position where we could introduce the steroidal A-ring. Our initial attempt to eliminate used conditions described by Gassman using trimethylsilyl triflate and Hünig's base in dichloromethane at $0{ }^{\circ} \mathrm{C} .{ }^{8}$ Two products were isolated from this, these being the desired enol ether derivative of compound $\mathbf{5}$ in $50 \%$ yield, and the silylated product $\mathbf{6}$ in $36 \%$ yield. We felt that this silylated intermediate might be more useful in subsequent transformations and so optimized for this serendipitous by-product by using 3 equivalents of reagents. Pleasingly, after just $1 \mathrm{~h}$ using this modified stoichiometry, we obtained an $81 \%$ yield of enol ether 6. Allylic oxidation using Corey-Yu conditions ${ }^{9}$ worked on both silylated and non-silylated frameworks, but with the former providing the better yield ( $67 \%$ vs $58 \%$ ) to give enone 7 . We felt that this new carbonyl would firstly allow us to introduce what would become the C-19 methyl (or indeed hydroxymethyl) and indeed provide a useful handle to introduce the steroidal A-ring. We therefore successfully deprotonated the cyclohexanone ring with lithium hexamethyldisilazide and acylated with ethyl chloroformate to give functionalized intermediate $\mathbf{8}$ as a single diastereoisomer, which is presumably a result of equilibration under the reaction conditions towards the thermodynamically preferred equatorial product.

It was postulated that strongly reducing conditions would result in the desired tricycle $\mathbf{1 0}$ via a reduction-eliminationreduction pathway. Using high pressure reducing conditions gave a single product, which we believed to be this. In actual fact, we had made the regioisomeric system 9. Unaware of this, we proceeded with the Robinson annulation using methyl vinyl ketone and were delighted to see clean conversion of the compound we thought to be tricycle 10. However, the ${ }^{1} \mathrm{H}$ NMR spectrum of our purported steroidal framework on closer examination appeared to be subtly but critically different to that which we expected, and we ultimately assigned it to the tetracyclic steroid-like saturated cyclopenta[c]phenanthrene framework 11. This was later confirmed by X-ray crystallographic analysis, which not only agreed with our proposed connectivity, but also verified the absolute stereochemistry of this very unusual system (Figure 4).

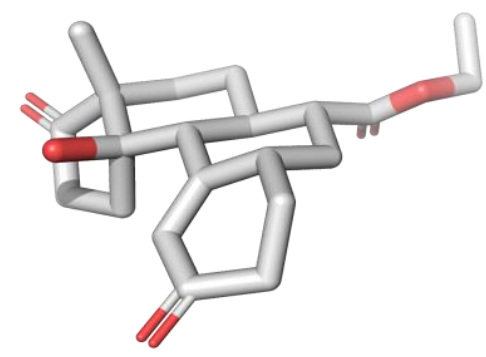

Figure 4. X-ray crystallography confirmed the structure of the intriguing tetracyclic, steroid-like framework 11 (CCDC : 1987209) 


\section{Conclusion}

In summary, we have successfully elaborated our initial terpenoid framework 1 stereoselectively and have also managed to synthesize an unusual steroidal constitutional isomer. Although it is clear that this tetracycle was not our intended target, it brought our attention to the paucity of these simple steroidal variations, which are in themselves structurally fascinating. We hope that this report will stimulate thought as to why this is the case. Future work will examine further reactivities of this intriguing scaffold as well as their pharmacological profiles.

\section{Acknowledgments}

We thank King's College London and Dextra Laboratories for funding (to D. T.), and the Chemical Analysis Facility at the University of Reading for access to an X-ray diffractometer.

\section{References and notes}

1. For recent reviews on steroid synthesis, see (a) Khatri, H. R.; Carney, N.; Rutkoski, R.; Bhattarai, B.; Nagorny, P. Eur. J. Org. Chem. 2020, 755. (b) Reguera, L.; Attorresi, C. I.; Ramírez, J. A.; Rivera, D. G. Beilstein J. Org. Chem. 2019, 15, 1236. (c) Mackay, E. G.; Sherburn, M. S. Synthesis 2015, 47, 1. (d) Gupta, P.; Panda, G. Eur. J. Org. Chem. 2014, 8004.

2. Newman, D. J.; Cragg, G. M. J. Nat. Prod. 2012, 75, 311.
3. (a) Qian, M.; Covey, D. F. Adv. Synth. Catal. 2010, 352, 2057. (b) Scaglione, J. B.; Jastrzebska, I.; Krishnan, K.; Li, P.; Akk, G.; Manion, B. D.; Benz, A.; Taylor, A.; Rath, N. P.; Evers, A. S.; Zorumski, C. F.; Mennerick, S.; Covey, D. F. J. Med. Chem. 2008, 51, 1309. (c) Jastrzebska, I.; Scaglione, J. B.; DeKoster, G. T.; Rath, N. P.; Covey, D. F. J. Org. Chem. 2007, 72, 4837.

4. Nazarov, I. N.; Nagibina, T. D. Zh. Obshch. Khim. 1950, 20, 531.

5. Townsend, D.; Shankland, K.; Weymouth-Wilson, A.; Komsta, Z.; Evans, T.; Cobb, A. J. A. Chem. Eur. J. 2020, 26, 3504.

6. Tormo, J.; Hays, D. S.; Fu, G. C. J. Org. Chem. 1998, 63, 5296. (unfortunately the catalytic conditions were not high yielding).

7. Nicolaou, K. C.; Zhong, Y. L.; Baran, P. S. J. Am. Chem. Soc. 2000, 122, 7596 .

8. Gassman, P. G.; Burns, S. J.; Pfister, K. B. J. Org. Chem. 1993, $58,1449$.

9. Yu, J.-Q.; Corey, E. J. J. Am. Chem. Soc. 2003, 125, 3232.

\section{Supplementary Material}

Supplementary material for the synthesis of all compounds described along with spectroscopic data is available free of charge.

\section{Click here to remove instruction text...}

